\title{
Pelatihan pemanfaatan alat peraga bagi Guru SD Muhammadiyah di Sukoharjo dalam menghadapi era Revolusi Industri 4.0
}

\author{
Fuad Anwar ${ }^{1}$, Kusumandari ${ }^{2}$, Yofentina Iriani ${ }^{3}$, Mohtar Yunianto ${ }^{4^{*}}$ \\ Program Studi Fisika Universitas Sebelas Maret ${ }^{1,2,3,4}$ \\ mohtaryunianto@staff.uns.ac.id ${ }^{4 *}$
}

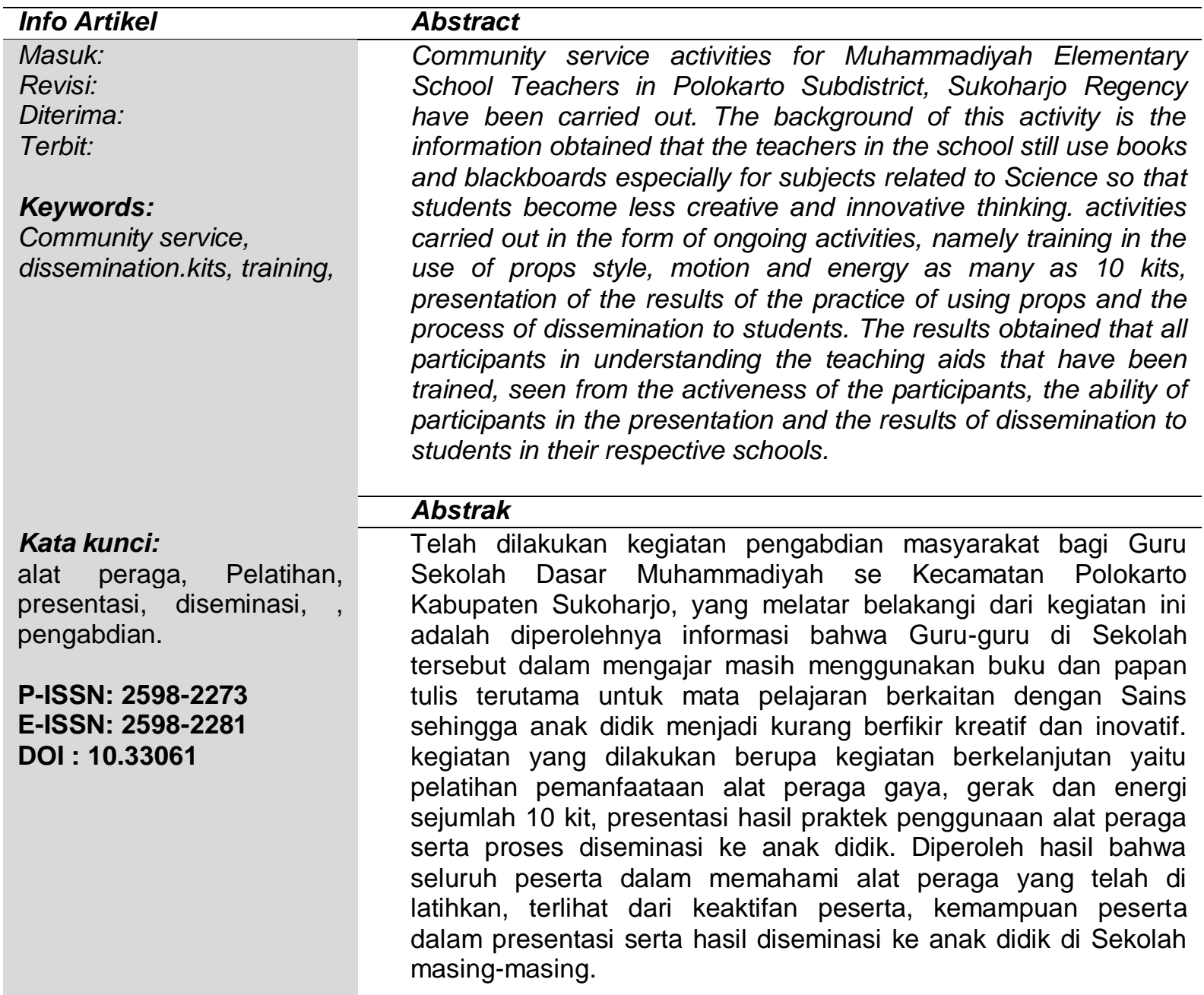

\section{PENDAHULUAN}

Ketercapaian tujuan pembelajaran yang telah ditetapkan merupakan hal yang menjadi target capaian dalam hal efektifitas proses belajar mengajar, sedangkan efesiensi dapat dilihat dari kualitas komunikasi antara guru dan siswa yang intensif, berkesinambungan dan tidak menimbulkan salah pengertian, khususnya tentang pemahaman konsep/materi ajar. Azhar Arsyad (2003) menyatakan bahwa dalam suatu proses belajar mengajar, ada dua unsur yang sangat penting, yaitu metode mengajar, dan media pembelajaran, kedua aspek ini saling berkaitan. Pemilihan metode mengajar tertentu akan mempengaruhi media ataupun alat peraga pemebelajaran yang digunakan. Alat pembelajaran merupakan alat bantu mengajar 
yang turut mempengaruhi iklim, kondisi, dan lingkungan belajar yang ditata dan diciptakan guru.

Dalam kenyataannya masalah penggunaan alat peraga pembelajaran ini menjadi hal yang sering di abaikan dalam menjelaskan suatu materi pembelajaran. Alasan yang sering muncul antara lain: terbatasnya waktu untuk membuat persiapan mengajar, sulit mencari alat peraga yang tepat, tidak tersedia biaya. Hal ini sebenarnya tidak perlu terjadi jika setiap guru telah membekali diri dengan pengetahuan dan keterampilan dalam hal media pembelajaran. Hal tersebut juga terjadi di Sekolah Muhammadiyah di Kecamatan Polokarto Kabupaten Sukoharjo, dari informasi yang diperoleh bahwa Guru dalam menyampaikan pembelajaran hanya menggunakan media buku dan papan tulis sehingga siswa didik menjadi jenuh dan kurang konsentrasi dalam menerima pelajaran, di Kecamatan Polokarto sendiri terdiri dari 11 sekolah Muhammadiyah setingkat Sekolah Dasar.

Pembelajaran sains yang memiliki tingkat kesulitan dan keabstrakan konsep yang lebih tinggi tentu memerlukan cara dan metode komunikasi yang berbeda dengan mata pelajaran lain. Ditinjau dari obyek pembelajaran sains yang abstrak tersebut maka diperlukan media maupun alat peraga khusus untuk menyampaikannya. Media yang dapat digunakan untuk menyampaikan materi atau konsep sains dapat berasal dari obyek yang sudah ada maupun media yang khusus dibuat untuk hal tersebut.

Media pengajaran merupakan wadah dan penyalur pesan dari sumber pesan,dalam hal ini guru, kepada penerima pesan ( Rusdi R, 2007), dalam hal ini siswa. media diartikan dengan segala bentuk dan saluran yang dapat dipergunakan untuk proses penyalur pesan ( Arief Sadiman, 2003). Penggunaaan media maupun alat peraga secara kreatif akan memungkinkan siswa untuk belajar lebih baik dan dapat meningkatkan performan mereka sesuai dengan tujuan yang ingin dicapai. Media pengajaran yang digunakan dapat berupa peralatan yang efektif yaitu alat peraga.

Alat peraga pengajaran adalah alat-alat yang digunakan guru ketika mengajar untuk membantu memperjelas materi pelajaran yang disampaikannya kepada siswa dan mencegah terjadinya verbalisme pada diri siswa. Menurut E.T.Ruseffendi (1994) Alat peraga, yaitu benda atau alat untuk menerangkan atau mewujudkan konsep dasar, sedangkan menurut Aristo Rohadi (2003), Alat peraga adalah alat (benda) yang digunakan untuk memperagakan fakta, konsep, prinsip, atau prosedur tertentu agar tampak lebih nyata atau konkrit. Dalam proses pembelajaran diperlukan media atau alat peraga yang dapat mempertinggi proses dan hasil belajar yang berkenaan dengan taraf berpikir siswa. Piaget membagi perkembangan kognitif kedalam empat fase, yaitu fase sensorimotor untuk anak usia 0-2 tahun, fase praoperasional untuk anak usia 2-7 tahun, fase operasi konkret untuk anak usia 7-11 tahun, dan fase operasi formal untuk anak usia 12 tahun keatas (Jamaris, 2006).

Kegiatan yang dilakukan dalam upaya menghadapi era Revolusi Industri 4.0 dimana pemanfaatan teknologi sangat penting maka dilakukan kegiatan berupa pengenalan dalam bentuk pelatihan menafaatan alat peraga bagi Guru Sekolah tingkat Dasar, adapaun tujuan dari kegiatan ini adalah memberikan alternatif kegiatan belajar mengajar yang umumnya berupa ceramah dikelas yang menjadikan siswa bosan dengan kegiatan pemanfaatan alat peraga agar siswa tidak merasa 
bosan terlebih akan measah daya nalar dan kreatifitas siswa didik, sehingga tujuan pembelajaran akan tercapai.

\section{RUMUSAN MASALAH}

Berdasarkan pendahuluan diperoleh informasi bahwa Guru-guru di Sekolah Dasar Muhammadiyah se Kecamatan Polokarto dalam mengajar masih menggunakan buku dan papan tulis terutama untuk mata pelajaran berkaitan dengan Sains sehingga anak didik menjadi kurang berfikir kreatif dan inovatif, sehingga perlu ada upaya untuk mengubah pola mengajar terutama dengan memanfaatan media pembelajaran berupa alat peraga.

\section{METODE PENELITIAN}

Metode yang digunakan dalam kegiatan pengabdian ini dilakukan dengan 3 tahapan yang disajikan dalam bagan sebagai berikut :

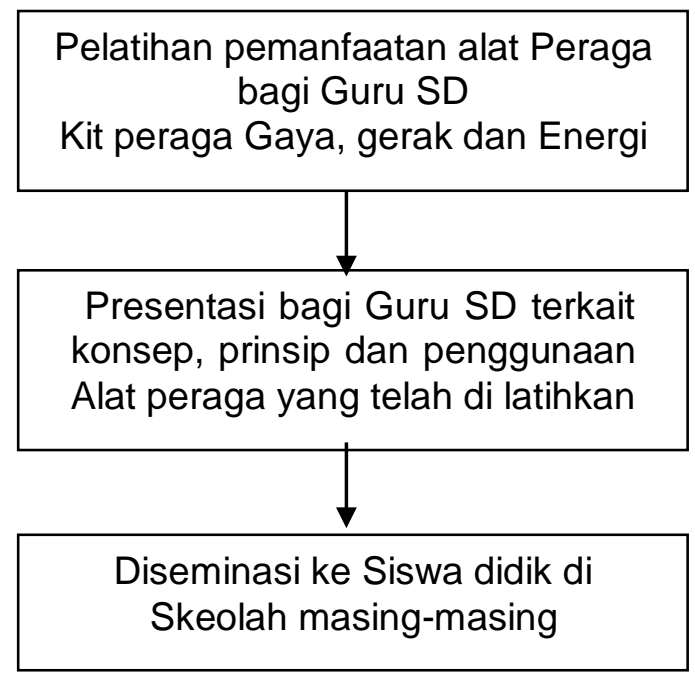

Gambar 1. Urutan Metode Pengabdian

\section{PEMBAHASAN}

Kegiatan peningkatan kemampuan Guru Sekolah Dasar Muhammadiyah seKecamatan Polokarto telah dilakukan dengan 3 tahapan, tahapan awal yang dilakukan adalah melalui pelatihan pemanfaatan alat peraga sains, semua guru perwakilan dari sekolah Muhammadiyah dibagikan alat peraga sains untuk materi Gaya, gerak dan energi yang terdiri dari 10 modul, diantaranya adalah : Baling-baling terbang, Bunyi tik-tok, granat, ketapel balon, kereta magnet, klip melayang, kompas sederhana, mondar-mandir, serbuk besi menari dan juga terompet. Alat peraga tersebut bermanfaat untu memahamkan siswa berkaitan dengan materi Gaya, gerak dan energi, hasil dari kegiatan tahap awal ini adalah diperoleh informasi setelah melakukan peragaan dari semua alat peraga tersebut guru lebih memahami secara konsep yang berkaiatn dengan materi tersebut, adapun modul alat peraga tersebut 
sebagai tersaji pada Gambar 2 sedangkan pelaksanaan kegiatan pengabdian tersaji pada Gambar 3.

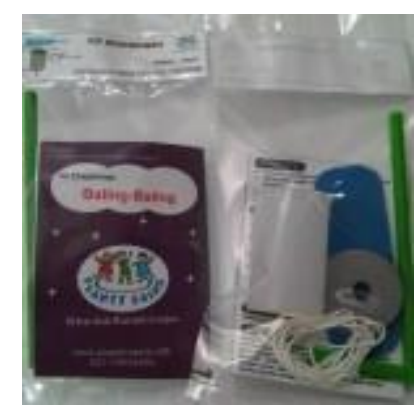

Baling-baling terbang

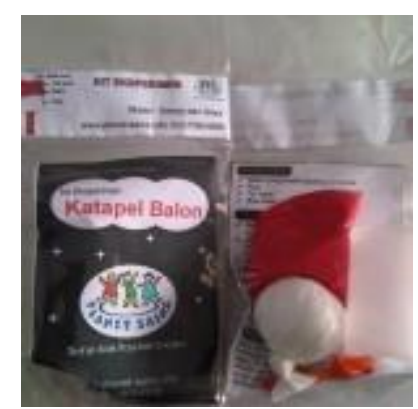

Katapel balon

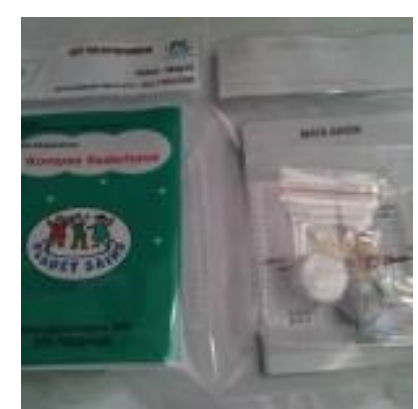

Kompas sederhana

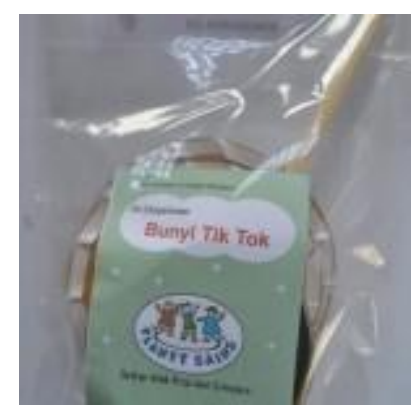

Bunyi tik tok

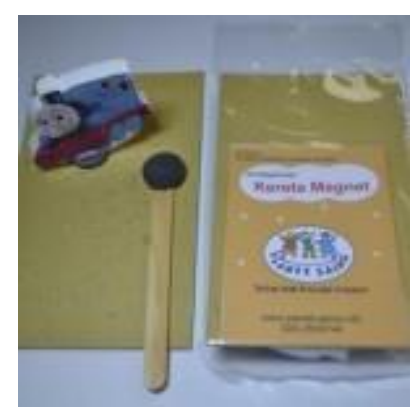

Kereta magnet

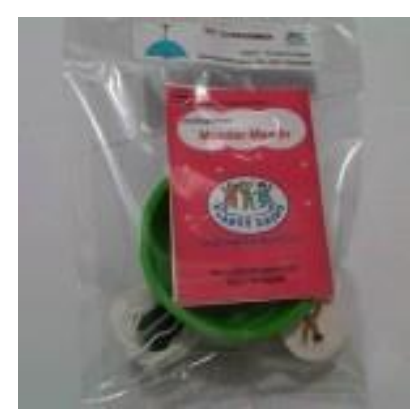

Mondar-mandir

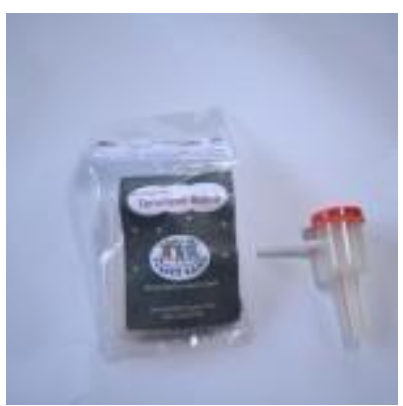

Terompet balon

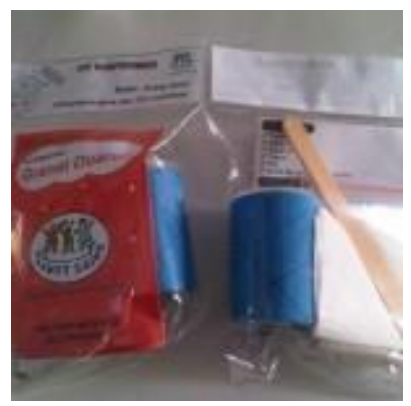

Granat duarrr!

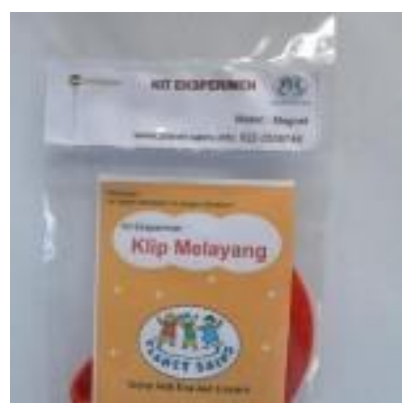

Klip melayang

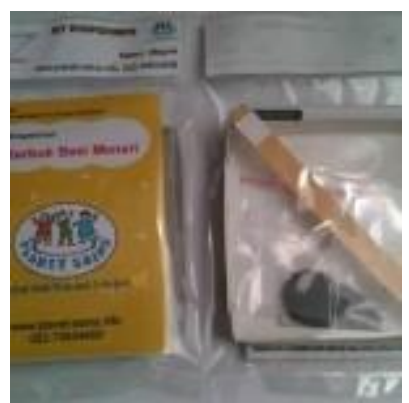

Serbuk besi menari

Gambar 2. Kit alat peraga yang di gunakan dalam pelatihan 

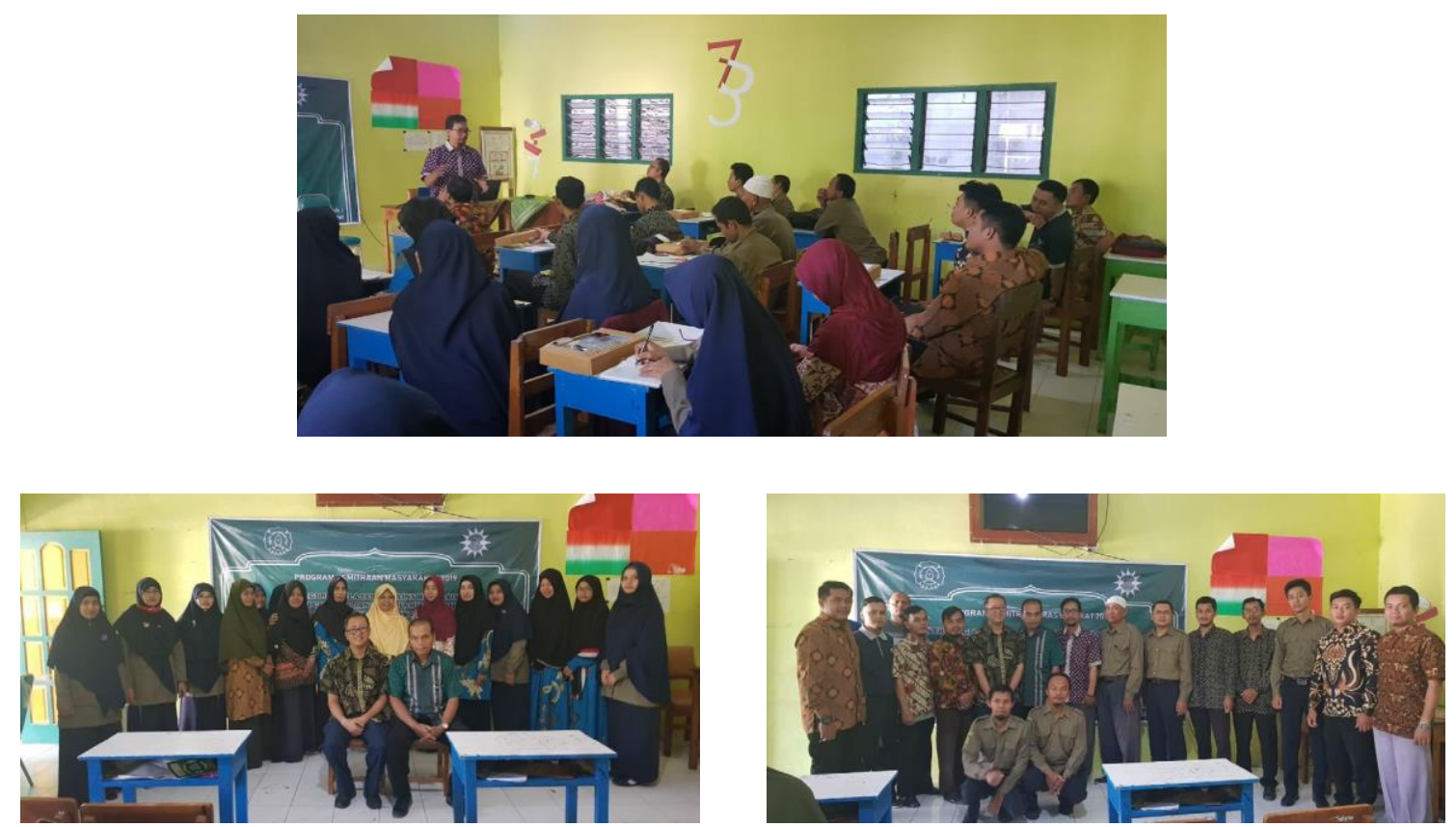

Gambar 3. Pelaksanaan dan peserta pelatihan

Kegiatan lanjutan setelah pelaksanaan pelatihan pemanfaatan alat peraga adalah presentasi secara kelompok, kegiatan presentasi dilakukan dalam upaya menggali informasi ketercapaian tujuan pelatihan bagi peserta, hasil dari presentasi diperoleh informasi hampir sebagian besar peserta mampu menggunakan alat peraga dan mampu menjelaskan teori dan manfaat yang diperoleh serta mampu menjelaskan kaitannya dengan materi sains untuk siswa SD.

Akhir dari kegiatan pengabdian adalah proses diseminasi kegiatan pelatihan ke siswa sekolah, dari hasil sampling ke beberapa sekolah diperoleh informasi bahwa Guru dalam menyampaikan materi sains yang sebelumnya menggunakan media buku dan papan tulis kemudian di lengkapi dengan penggunaan alat peraga menjadikan siswa ebih mudah memahami materi yang disampaiakan serta dapat melakukan percobaan secara langusng terkait materi yang dijelaskan.

\section{SIMPULAN}

Telah dilakukan upaya untuk menghadapi era Revolusi Industri 4.0 bagi Guru Sekolah Dasar Muhammadiyah di Kecamatan Polokarto Kab Sukoharjo, kegiatan yang dilakukan dilaksanakan dalam 3 tahap yaitu pelatihan pemanfaatan alat peraga sains dengan materi gaya, gerak dan energi, pelaksanaan presentasi serta diseminasi ke anak didik, hasilnya adalah seluruh peserta mampu menggunakan alat peraga tersebut, daat mempresentasikan dengan baik serta dapat dengan mudah menjelaskan ke anak didik berkaitan materi yang berhubungan dengan alat peraga yang di latihkan. 


\section{REFERENCES}

Azhar Arsyad, 2003. Media Pembelajaran, Raja Grafindo Persada, Jakarta Arief S.Sadiman, dan kawan-kawan, 2003, Media Pendidikan Pengertian, Pengembangan dan Pemanfaatannya, Raja Grafindo Persada,Jakarta,

Aristo Rahardi. 2003. Media pembelajaran. Jakarta:Dirjen Dikdasmen.

Iklima, Maulidiyatul. 2014. Penerapan Model Pembelajaran Inquiry Training. SKRIPSI. Program Studi Pendidikan Fisika, Jurusan Fisika FMIPA Universitas Negeri Malang.

Jamaris, Martini. 2006. Perkembangan dan Pengembangan Anak Usia Taman Kanak-Kanak. Jakarta: Grasindo.

Rusdi Susilana \& Cepi Riyana, 2007. Media Pembelajaran hakikat pengembangan, pemanfaatan, dan Penilaian, Wacana Prima, Bandung 